\title{
The Challenge of Implementing Preferred Gender Pronouns: Queer Autonomy in the Age of Information Technologies
}

https://doi.org/10.51897/interalia/BTAW6071

Zooey Sophia Pook

New Mexico State University

\begin{abstract}
A preferred gender pronoun or PGP is the gender pronoun, or set of gender pronouns, an individual uses to represent themselves and by which they would like others to use when they represent them (PFLAG). The use of PGPs is meant to show respect to the autonomy of individuals whose gender identity may not conform to the appearance of others, or individuals whose identity is gender non-binary (HRC). The use of PGPs is suggested as a best practice by nearly every major LGBT+ organization in the US (PFLAG, HRC, etc.). Today, systems for implementing PGPs exist everywhere from college applications, hospital intake forms, dating websites, and beyond. While the use of PGPs shows respect for transgender and gender nonconforming individuals, these practices have unintended consequences as they contribute to the ever-expanding economies of data collection, made possible through the rise of information technologies. This work will explore questions of economy and power related to the collection of PGPs and the challenge of queer autonomy in the age of neoliberal capitalism.
\end{abstract}

Keywords: preferred pronouns, neoliberalism, queer theory, algorithms, information capital

\section{Introduction}

A preferred gender pronoun or PGP is the gender pronoun, or set of gender pronouns, an individual uses to represent themselves and which they would like others to use when they represent them (PFLAG). The use of PGPs is meant to show respect for the autonomy of individuals whose gender identity may not conform to the way they are perceived by others, or individuals whose identity is gender non-binary (HRC). The use of PGPs is suggested as a best practice by nearly every major LGBT + organization in the US (PFLAG, HRC, etc.). Today, systems for implementing PGPs exist everywhere, from college applications, hospital intake forms, dating websites, and beyond. While the use of PGPs shows respect for transgender and gender nonconforming individuals, these practices have unintended consequences as they contribute to the ever-expanding economies of data collection, made possible through the rise of information technologies. This work will explore questions of economy and power related to the collection of PGPs and the challenge of queer autonomy in the age of neoliberal capitalism.

Internet technologies dominate our daily lives. Whether it is by computer, tablet, or cell phone, our lives are mediated by the interfaces of our personal screens. These information technologies create a unique opportunity through which data are captured based on our browsing habits; content is generated to keep each of us clicking by providing us with content specific to our interests. This data is capital, being sold, repackaged, and sold back to us in a variety of ever-expanding packages. Therefore, our ever-expanding gender identities, which we provide to Facebook, dating websites, etc. do 
not present a disturbance or a challenge in these digital spaces in the same way they once would have in physical spaces (schools, the workplace, etc.), but instead mimic and contribute to the work of algorithms in their collection and production of ever greater configurations of data. For instance, Amazon does not care if I am queer; its algorithms will generate an ad for Janet Mock's latest book as easily as they would an ad for one by Bill O'Reilly, based on what I shared on Facebook or what I searched for on Google earlier. The collection and use of pronouns exists in a much larger context on the internet, as everything from race to sexuality to any imagined identity marker or personal preference is utilized by algorithms for its data potential. This generates the need to think about how we share personal information as queer beings and how our practices might contribute to processes of power and economy, recognizing how our participation on the internet is monetized. Since I am a transgender woman and Director of an LGBT + office at a US university, it is of important concern to me to begin a conversation about how queer autonomy relates to the internet and the ways in which we collect information. This work will make an intervention into queer scholarship by imagining how emerging political and media theory can help to investigate unfolding questions of LGBT+ internet usage.

\section{Changing Technologies, Changing Power}

Capital is no longer static. Internet and algorithmic technologies have increased the scope of capitalism through the constant participation of subjects with internet technologies. These technologies, through their multidimensional omnipresence and capacity to retain and reconfigure data, have blurred the boundaries of work/leisure, private/public, and consumer/producer, reimagining all social space as that of capitalist production. Humans exist in concert with these technologies, contributing to and being produced through their communication with algorithms, which have the power to make and place bets on resources all over the world in a matter of seconds. This global information economy is a product of the evolution of neoliberalism and the expanding efficiencies of global capital, and it speaks to the reduction of all things, human and non-human, to data in which resources and information alike flow through digital networks. Power is no longer a singular locatable thing, as Deleuze notes, with singular focal points such as the school, prison, factory, etc. as it was in Foucault's discipline society, but is managed through access to information and resources on networks, and the system of credit and debt (Deleuze, 2000: 89). This is not a new form of power, but rather still capital; it is a mutation made possible by technology, and it is more efficient in grasp and control (2000: 90). It is the effective management of the very global insecurity that capital creates. Information technologies make possible the extension of the neoliberal horizon over all things human and machine, interchangeable in networks of machinic formations (Lazzarato, 2014: 35). Hardt and Negri's notion of empire posits this digital mutation of capital nicely when they explain that, "empire posits a regime that encompasses... spacial totality" and "presents its rule not as a transitory moment in the movement of history, but as a regime with no temporal boundaries and in this sense is outside of history or at the end of history" (Hardt and Negri, 2000: xiv-xv). In short, capital is no longer any single locatable thing, but it is our relation to others, ourselves, and the world (Invisible Committee, 2007: 91). It is 
a neoliberalist orientation made possible by the expanse of internet technologies from the West around the globe. We are ever more oriented through our technologies; this is already a growing reality of Western life but one that is quickly becoming more apparent elsewhere.

Internet experience is dictated by the work of algorithms. As Ed Finn puts it, algorithms are "cultural machines," because they are not only created by us, but they effect and shape us, determining how we exist, in return (2017: 48). Whether it is an app navigating us to a new location, Facebook communication with friends, picking out a movie or restaurant, or even choosing a mate, we use algorithmic technologies in every step of our daily existences. While most of us do not know what goes on behind the screen of our devices, we engage with them nonetheless, exhibiting a great deal of faith when we rely on them. In What Algorithms Want, Ed Finn explores the long-lasting analogy of algorithm as religion, citing the work of both George Dyson and Eric Chandler, writing:

perhaps the best analogy was offered at the IEEE Computer Society in 1988: 'Software and cathedrals are much the same-first we build them, then we pray.' This was meant as a joke, of course, but it hides a deeper truth about our relationship to the figure of the algorithm today. The architecture of code relies on a structure of belief as well as a logical organization of bits. (2017: 13)

There is a faith we put in their processes, and this faith, as it materializes through the Western ritual of our device use, shapes us and determines our worldly orientation. It is not surprising then that our constant need to open our phones, laptops, or tablets is big business. Former design ethicist at Google, Tristan Harris (Casey, 2017), likens opening our personal technology to pulling the lever on a slot machine, in which we wait in excitement, constantly refreshing our feeds to see if we've gotten a new social media notification, message alert, or email. For Harris, what then emerges is something he calls the "attention economy," where there is no shortage of information, but a shortage of users' time, which produces a hyper competitive space where companies compete to monopolize user head space through ever quicker and less substantial content. This content is personalized, through the use of algorithmic technologies, and marks a stark contrast to earlier forms of media, surrounding or encapsulating us in an experience of capital that does not turn off, is without limits, and presents itself as reality. Wendy Chun explains this dimensional difference in experience and shift in user orientation with computer technologies by saying that "Fiber optics threaten an infinite open circle of the 'representable'-they melt and stretch the glass so that nothing screens the subject from the circulation and proliferation of images. At the same time, they displace representation by code" (Chun, 2008). What emerges through our participation with information technologies is a reduction of the human and non-human alike to the data of capital; we are living digital lives. There is no distinction between the neoliberal citizen and the world.

Internet technologies separate themselves from former medias in their multidimensional level of engagement. The algorithm speaks back to us and engages us in the form of ever emerging personalized content and choices. It is through interactivity, as Marc Andrejvic puts it, that the computer 
now hyper produces the kind of surveillance that the tv offered, a la Jhally and Livant's reading of Dallas Smythe, maximizing the commodification of our leisure and dramatically altering the ways we think, act, and engage with the world (Andrejvic, 2000: 813). Andrejevic argues that this algorithmic communication with users produces what he calls digital enclosures, which are infinite feedback loops to keep an internet user clicking and producing more data and revenue. Thus, it is important to recognize that far beyond surveillance, neoliberal governance is generative; we are producing constant revenue with our internet usage. The content and choices that then emerge within a user's browsing experience are certainly not democratic or random, but purposely designed through the programming of algorithms to maximize data production. As Joshua Reeves' work in rhetoric offers,

the Web's rhetorical biases are expressed by the orientation of audiences toward logicized multitextual consumption. Web users are always inundated with a staggering number of 'relevant' possibilities, a ubiquitous rhetoric of the possible that encourages them to expand and renegotiate their media experience (see Craig and Flood). These fulfilled possibilities cohere into the rhetorical flows by which users are caught in unexpected patterns of participation, engaging issues, researching products, and exploring topics that while not preordained have been offered to them through a digital rhetoric that is heavily biased toward keeping its users connected to the Web. (2013: 325)

The mechanisms and the machinery guiding our experience on the internet is directed, serving larger purposes of an economy and governance that emerges through our participation with these technologies. Jodi Dean takes this argument a step further in her 2011 work, Blog Theory, offering that these enclosures or ever emerging content possibilities are essentially algorithmic traps, in which every click brings us closer to jouissance but is essentially unfulfilling, thus engaging us in ever further clicks (2011: 59). These works, along with a number of other important studies, such as those of Jim Brown, Steven Shaviro, and Steve Holmes, which cut across political theory, media theory, and rhetoric, are an important tool for creating what lan Bogost refers to as an algorithmic literacy, or in short, the ability to read and recognize how algorithms shape and structure our experiences with these technologies. I contend that an algorithmic literacy will be an important tool for queer scholars and community activists for thinking about how our collection of data on gender identity participates with larger social and economic technologies of information. The democratic hopes for the internet, at its conception, from many scholars and activists are deeply problematized by how these technologies function. While it is true that more voices can be heard, and more opinions shared, independent voices are not afforded equal space and time amongst the ever more cluttered competition of corporations vying for users' attention. This has come up repeatedly in the battle for net neutrality in the US (Fiegerman, 2018). However, what is more concerning than what appears on the surface of web browsing is that the machinery and mechanics of the internet are essentially designed, decided upon, and maintained by a small group of technological elites emerging from cybernetics and computer engineering. What would manifest from earlier workings of engineers and computer specialists in organizations like IEEE (Institute of Electronic and Electrical Engineers), who set protocol for technical 
standards, would be a small group of technical experts dictating the internet's protocols (Galloway, 2006: 189). While the IETF (Internet Engineering Task Force), where most internet initiatives begin today, is open and features public discussion, it is produced in a homogenous platform where technological innovation occurs though the processes of standardization and universality (2006: 191-95). This standardization and universality of experience assures that the ways we use the internet are singular and are directed through larger processes of neoliberalist economics. Curtis White aptly describes this technocratic shift: whereas previously the unskilled masses would replace a skilled and elite minority as technological advancement made a particular task easier (think of the assembly line), today the opposite is occurring: a small number of technologically skilled individuals hold the keys to our economy as they reimagine work, government, and our new social landscape (2015: 22). As such, the new governors are tech people imagining and materializing the texture of our neoliberal landscape (Invisible Committee, 2014: 106). Power exists through the capacity to interact with, store, and reconfigure the massive amounts of data capital constantly being produced, and this technological capacity certainly extends beyond the reach of individual citizens. Internet users are all producing free labor through the use of internet technologies, monetized and profited on by these wealthy global elites. As Mackenzie Wark states, "with the commodification of information comes its vectoralization. Extracting a surplus from information requires technologies capable of transporting information through space, but also through time" (2014: 318). Despite the appearances of spontaneous emergence of protocol, open software, and the freedom to speak, access to the internet is homogenized, and flows of capital and information are decidedly directed.

The internet is the new locus of economy and power. The new city becomes simply points of network access, as culture becomes interaction between points in digital networks. It is important to think about identity and data practices in line with these emerging technologies and in consideration of larger flows of information and capital. "The streets are dead capital," as Rita Raley proclaims, and it will be necessary to think about resistance and our queer identities in new ways (2009: 1). The battle for political power and autonomy, in many important ways, has shifted to the internet.

\section{The Personal Is Not Political for an Algorithm}

Queer scholarship and activism may not yet have the necessary tools to adequately think about, challenge, or offer resistance to the technologies emerging under neoliberalism. Far from being exclusionary, information technologies are inclusionary; their function is appropriation. They do not mimic the disciplinary tools of a previous political age but instead function through their reduction of difference to data potential. Therefor the vast array of queer works which illustrate the ways in which queer bodies resisted their domination and offered possibilities for reimaging social difference (Butler Gender Trouble, Halberstam, Salamon, Foucault Discipline and Punish, etc.), while entirely useful previously, do not offer much when we think about the changing function and scope of neoliberal governance. Many of the theoretical tools, such as deconstruction and historicism, or notions like embodiment or performativity, are ill suited to challenge information technologies because in many ways the function of algorithms are already queer: they are slippery, affective, and evolving, matching 
the a-political, boundless nature of neoliberal capitalism. Indeed, the personal is not political any longer, as so many queer activists once contended; nothing really is political-it is data and it is possible revenue. It is useful to consider here, at least briefly, the social-political history from which neoliberal governance and technologies arose to make sense of our participation with these systems and the tools of resistance at our disposal. As the technological developments were arising which would make neoliberal governance possible, a significant shift in the ideologies of Leftist protest and politics was also occurring. As Jodi Dean succinctly describes,

In brief, the late 1960s and early 1970s witnessed a set of profound changes in the world economy, changes associated with declines in economic growth and increases in inflation and unemployment... powerful figures in the corporate and finance sectors took this opportunity to dismantle the welfare state (by privatizing public holdings, cutting back on public services, and rewriting laws for the benefit of corporations). For the most part, the American left seemed relatively unaware of the ways business was acting as a class to consolidate political power-a fundamental component of which was the passage of a set of campaign finance laws establishing the rights of corporations to contribute unlimited amounts of money to political parties and political action committees. ${ }^{21}$ Instead, coming out of the movements associated with 1968, increasingly prominent voices on the left empathized and fought for personal freedoms, freedoms from parental and state constraints as well as freedoms for the expression of differences of race, sex and sexuality. While these ideals were situated within movements for social justice, their coexistence was precarious, as tensions at the time between workers and students made clear. (2011: 33)

What emerged from this period on the Left was a division between those more focused on matters of identity and those more concerned with divisions of wealth and conditions of the working class. Simultaneously, those on the Right worked to break down economic regulations, while fighting against what they considered to be an inflated, overly large government. This work of the Right to delegitimize the State, as Dean explains, was unwittingly complimented by work on the Left engaged with a variety of social issues, or what we might call identity politics, as "the state seemed but another repressive authority, its provisions tied to the sexism of the traditional family and the racism of the white mainstream" (2011: 34). What would emerge side by side with a number of social victories for minority groups post 1968, as the Left fought for civil rights and protections, was an evolution of capital that would provide new barriers to power. This was made possible through the destruction of several economic regulations and erosion of monopoly laws which would lead to the rise of multinational corporations, postfordist labor, and, eventually, with the technological innovation of the internet, the monetization of data and the possibilities for real time global investment. A new kind of politics and a new kind of capital was converging with a new kind of governance; appropriation would be its method of control. Here, it should not be viewed as coincidental, although certainly arguments are to be made about their sincerity, that it was major corporations who came to the defense of 
LGBT + people in states like Indiana and North Carolina when state governments moved to enact oppressive legislation (McGregor, 2019). After all, as The Huffington Post noted, "the combined buying power of lesbian, gay, bisexual, and transgender adults in the U.S. hits $\$ 884$ billion-fighting on behalf of LGBT employees and stakeholders has logically become good business" (Ferro and Kaufman, 2016). Multinational corporations, including the United States' largest employer, Walmart, championed LGBT+ expression with a number of emerging protections in the workplace (Green and Pettypiece, 2016). This is not to be read as a vote of confidence in the actions of these corporations, as questions of inequity and oppression certainly do continue to loom within their operations, but an observation of a clearly changing trend in how capital functions. Neoliberalism is about inclusion.

Many of the tools of identity politics are, thus, ill-suited to effectively challenging the tools of neoliberalism, such as internet technologies, because they are oriented towards a model of governance as exclusionary, rather than the current capitalism of inclusion that I have described. While disciplines like queer theory, race studies, and feminist studies evolved from these political struggles over the last few decades, it is important to think about new tools for dealing with the evolving technological nature of capitalism. It may be argued that identity politics can be suited for the internet, with \#BlackLivesMatter and the Same Love campaigns serving as popular examples in the US, but this misunderstands the mechanisms and the machinery of the internet as a medium. Any message is secondary to its function as data, as every message is appropriated, deconstructed, and reduced to the code of capital. Here, a message may have semiotic value on the surface, but it is important to consider the way that information technologies appropriate that message, reifying the mechanisms of neoliberal capital. Participation with these technologies strengthens the inequity of the global capitalist landscape, and our inclusion is appropriation on its terms. It is also important to consider that perhaps the most serious resistance movements to global capital quite recently were the online movements of Anonymous and Wikileaks, whose impacts arose from both their anonymity and their subversion or misuse of internet technologies, rather than their use of them, thus separating them in both form and function. Anonymous inhabits a Dionysian energy, argues Gabriella Coleman; its activists mix playfulness in their full out assault on sources of power they believe have committed wrongdoing against the populace, often associated with violating a belief in free speech they hold sacred for the internet (Coleman, 2014: 85). Some examples include DDoS attacks, phishing efforts (attempts to engage organizations online to fraudulently allow access to secure material), and acts of doxing (publicly releasing the private information of institutions or individuals) against the government of Tunisia, The Church of Scientology, and Visa, Mastercard, and PayPal—whose representatives denied donations made to Wikileaks (a whistleblowing website that releases leaked information to promote transparency and to fight corruption). Anons (members of Anonymous) communicate through chatrooms in which anyone can join, throw out an idea, and emerge as part of a plan to take action. At its highest point, estimates offer that up to 10,000 individuals from around the world participated simultaneously in some form in coordination with Anonymous (Knappenberger, 2012). Similarly, Wikileaks is a group that used software to create encrypted conversation for whistleblowers to report abuses of power, which Wikileaks would then share (or leak) publicly to discredit the alleged abusers. Their work included notable leaks alleging wrongdoing in the Iraq war, corruption in the 
government of Tunisia, fraudulent activity by major banks, and quite recently, an email chain between Hillary Clinton and staffers from the Democratic National Committee, which may have impacted her election chances. The work of these two groups, and numerous others, has forced governments and the public to rethink internet freedom and security, investing in security software and changing communication practices. Members associated with these groups who subverted, misused, and disrupted these neoliberal technologies have faced exorbitant criminal charges that far exceed the prison sentences for crimes related to physical protest, evidencing the higher political stakes of the digital landscape (Coleman, 2014: 159).

In a project aimed at engaging queerness in subversion of internet technologies, queer media theorist Zach Blas engaged with and wrote about an art group called Queer Technologies - who began development on a Facial Weaponization Suite. Blas' work is a useful example of the kind of undertaking for queer theorists to engage in, thinking about possible forms of resistance to neoliberal technologies. Playing on the notion of "fag face" (the idea that a gay person's face is recognizable as such), Queer Technologies developed masks comprised of many gay men's faces in one single $3 \mathrm{~d}$ model that when worn would throw off facial recognition software. Blas's work builds on a 2001 piece by media theorist Phillip Agre, which outlines the potential dangers of facial recognition software. These works, which examine concepts of capture and surveillance, address many of the same problems with data mining such as the potential to store and appropriate personal information/likeness, etc. Similarly, Jasbir Puar's Terrorist Assemblages, although a work of political theory, reimagines the neoliberal network and possible subversion through counter networks of queer and other experience. Puar's work reimagines the notion of assemblage to pose possible resistance to neoliberal networks, imagining tactics and strategies that challenge power as it constitutes itself today through technologies of appropriation. These works, and others beginning to emerge as part of important conversations about queer engagement with neoliberal technologies, recognizing the larger apparatuses of power and capital that shape them. These works are distinguished from previous or more traditional scholarship about LGBT+ usage on the internet (Rawson, Seiebler, Rak, etc.) through their recognition of the technologies of information capital, which much scholarship regarding identity and internet usage doesn't adequately account for. These works remain more focused on concerns of a governance of exclusion such as representation and discipline, missing how internet technologies function differently than previous medias.

\section{Conclusion}

Important theoretical questions about autonomy, anonymity, and ethics present themselves when we consider queer digital participation and processes of data collection, such as those of PGPs. Specifically, the use and collection of preferred pronoun information for transgender and gender non-conforming people offers an important opportunity to explore issues of ethics and queer autonomy on the internet because it evidences the challenges of inclusion/exclusion and representation that information technologies bring. While recognizing preferred pronouns are important to the health and success of transgender and gender nonconforming persons, the collection of such 
information through internet technologies has unintended effects. The scope of data collection about gender and sexuality is only growing, as the capture of preferred pronouns in professional, medical, and educational settings suggests. It will be important for scholars and activists concerned with LGBT + autonomy to consider how information technologies function and to consider how queer practices contribute to or challenge their functions. Establishing an algorithmic literacy to make sense of and understand how internet technologies operate to appropriate identity through collection of data will be a necessary and critical tool for queer scholars and activists. As Alexander Galloway explains, "interfaces themselves are effects, in that they bring about transformations in material states. But at the same time interfaces are themselves the effects of other things, and thus tell the story of the larger forces that engender them" (Galloway, 2013a: vii). It is, therefore, necessary to understand how our own daily uses of technology arise from larger economic forces and how they contribute to our own changing human orientation and engagement with the world. PGPs position themselves as an important site for queer intervention, recognizing the extent of our own participations with these technologies, and offering a space to explore how theorists and activists might understand and challenge the ways that information technologies use LGBT+ data.

\section{Works Cited}

Agre, Philip E. (2001) "Your Face Is Not a Bar Code: Arguments Against Automatic Face Recognition in Public Places", Whole Earth, 106: 74-77, https://pages.gseis.ucla.edu/faculty/agre/barcode.html

Andrejvic, Mark (2000), "The Work of Being Watched: Interactive Media and the Exploitation of Self Disclosure", Media Studies: A Reader, Peter Marris (ed.), 3rd ed., New York, New York UP: 230248, https://doi.org/10.1080/07393180216561

Blas, Zach (2012), "Queer Darkness", Depletion Design: A Glossary of Network, 8: 127-133, https://networkcultures.org/_uploads/tod/TOD\#8_DEPLETION_DESIGN.pdf

Bogost, Ian (2007), Persuasive Games: The Expressive Power of Videogames, Cambridge (MA), The MIT Press, https://doi.org/10.7551/mitpress/5334.001.0001

(2008), "The Rhetoric of Video Games", The Ecology of Games: Connecting Youth, Games, and Learning, Katie Salen (ed.), The John D. and Catherine T. MacArthur Foundation Series on Digital Media and Learning, Cambridge (MA), The MIT Press: 117-140, https://se4n.org/papers/bogost-rhetoric.pdf

Brown, James Joseph, Jr. (2014), "The Machine That Therefore I Am", Philosophy \& Rhetoric, 47.4: 494-514, https://doi.org/10.5325/philrhet.47.4.0494

Butler, Judith (1990), Gender Trouble: Feminism and the Subversion of Identity, New York-London, Routledge.

Casey, Paul (dir.) (2016), "In Real Time with Bill Maher", Performance by Bill Maher and Tristan Harris, season 15, episode 17, HBO, 2 June 2017. Television.

Chun, Wendy Hui Kyong (2008), Control and Freedom: Power and Paranoia in the Age of Fiber Optics. Cambridge (MA), The MIT Press. 
Coleman, Gabriella (2014), Hacker, Hoaxer, Whistleblower, Spy: The Many Faces of Anonymous, London, New York, Verso.

Dean, Jodi (2011), Blog Theory: Feedback and Capture in the Circuits of Drive, Cambridge (MA), Polity Press.

Deleuze, Gilles (2000), "Postscript on the Societies of Control", Media Studies: A Reader, Peter Marris (ed.), 3rd ed., New York, New York UP: 3-7.

Ferro, Shane and Alexander C. Kaufman (2016), "How Corporate America Became A Major LGBT Ally", Huffington Post, 14 Sept. 2016, www.huffingtonpost.com/entry/corporateamericalgbtally_us_570e5c22e4b08a2d32b8840b

Fiegerman, Seth (2018), "The End of Net Neutrality Is Here", CNN. Cable News Network, 10 June 2018, https://money.cnn.com/2018/06/10/technology/net-neutrality/index.html

Finn, Ed (2017), What Algorithms Want: Imagination in the Age of Computing, Cambridge (MA), The MIT Press, https://doi.org/10.7551/mitpress/9780262035927.001.0001

Foucault, Michel (1977), Discipline and Punish: The Birth of the Prison, New York, Pantheon Books. . (1990), The History of Sexuality, Vol. 1: An Introduction, New York, Vintage Books.

Galloway, Alexander R. (2006), "Protocol vs Institutionalization", New Media Old Media: A History in Theory Reader, Wendy Hui Kyong Chun and Thomas Keenan (eds.), New York, Routledge: 187198. Print.

(2013a), The Interface Effect, Cambridge (MA), Polity Press.

. (2013b), "The Poverty of Philosophy: Realism and Post Fordism", Critical Inquiry, 39.2: 347366, https://doi.org/10.1086/668529

Green, Jeff and Shannon Pettypiece (2016), "Wal-Mart Joining Corporate Surge to Protect LGBT Employees", Chicago Tribune, 5 Dec. 2016, www.chicagotribune.com/business/ct-corporateequality-index-Igbt-employees20161205-story.html

Halberstam, J. (2005), In a Queer Time and Place: Transgender Bodies, Subcultural Lives, New York, New York UP.

Hardt, Michael and Antonio Negri (2000), Multitude: War and Democracy in the Age of Empire, Cambridge (MA), Harvard UP, 2000.

Holmes, Steve (2014), "Rhetorical Allegorithms in Bitcoin", Enculturation: a Journal of Rhetoric, Writing and Culture, 19 Aug. 2014, www.enculturation.net/rhetoricalallegorithms

Human Rights Campaign, "Glossary of Terms", www.hrc.org/resources/glossary-of-terms

__. "Talking About Pronouns in the Workplace", www.hrc.org/resources/talking-aboutpronouns-in-the-workplace

Invisible Committee (2007), The Coming Insurrection, Cambridge (MA), The MIT Press.

—_. (2014), To Our Friends, Cambridge (MA), The MIT Press.

Knappenberger, Brian (dir.) (2012), We Are Legion: The Story of the Hacktivists, Luminant Media, Film.

Lazzarato, Maurizio (2014), Signs and Machines: Capitalism and the Production of Subjectivity, Semiotext(e). 
McGregor, Jena (2016), "Corporate America's Embrace of Gay Rights Has Reached a Stunning Tipping Point", Washington Post, 5 Apr. 2016, www.washingtonpost.com/news/onleadership/wp/2016/04/05/corporateamericas-embraceof-gay-rights-has-reached-a-stunning-tippingpoint/?utm_term=.b525799c3d5e

PFLAG (2016), Our Children: Questions and Answers for Families of Lesbian, Gay, Bisexual, Transgender, Gender-Expansive and Queer Youth and Adults, https://pflag.org/sites/default/files/OUR\%20CHILDREN_PFLAGNational_FINAL.pdf

Pook, Zooey Sophia (2018), Queer is the New Capitalism: Neoliberal Technologies and a Blueprint for the Left Beyond Identity Politics, Diss. New Mexico State University, Thesis, https://www.academia.edu/36451709/QUEER_IS_THE_NEW_CAPITALISM_NEOLIBERAL_TECHN OLOGIES_AND_A_BLUEPRINT_FOR_THE_LEFT_BEYOND_IDENTITY_POLITICS

Puar, Jasbir K. (2007), Terrorist Assemblages: Homonationalism in Queer Times, Durham, Duke UP. https://doi.org/10.1215/9780822390442

Rak, Julie (2005), "The Digital Queer: Weblogs and Internet Identity", Inhabiting Multiple Worlds: Auto/Biography in an (Anti-)Global Age, 28.1: 166-182, https://doi.org/10.1353/bio.2005.0037

Raley, Rita (2009), Tactical Media, Minneapolis, U of Minnesota P.

Reeves, Joshua (2013), "Temptation and Its Discontents: Digital Rhetoric, Flow, and the Possible", Rhetoric Review, 32.3: 314-330, https://doi.org/10.1080/07350198.2013.797878

Salamon, Gayle (2010), Assuming a Body: Transgender and Rhetorics of Materiality, New York, Columbia UP, 2010.

Shaviro, Steven (2013), "Accelerationist Aesthetics: Necessary Inefficiency in Times of Real Subsumption", e-flux journal, 47, https://www.e-flux.com/journal/46/60070/accelerationistaesthetics-necessary-inefficiency-in-times-of-real-subsumption/

Siebler, Kay (2012), "Transgender Transitions: Sex/Gender Binaries in the Digital Age", Journal ofGay \& Lesbian Mental Health, 16.1: 74-99, https://doi.org/10.1080/19359705.2012.632751

Wark, McKenzie (2004), A Hacker Manifesto, Cambridge (MA), Harvard UP.

White, Curtis (2015), We, Robots: Staying Human in the Age of Big Data, Brooklyn, Melville House. 